ORIGINAL ARTICLE

\title{
A pilot study to evaluate the safety and feasibility of the administration of AZT/3TC fixed dose combination to HIV infected pregnant women and their infants in Rio de Janeiro, Brazil
}

\author{
J S Lambert, S A Nogueira, T Abreu, E S Machado, T P Costa, M Bondarovsky, M Andrade, \\ M Halpern, R Barbosa, M Perez
}

Sex Transm Infect 2003;79:448-452

See end of article for authors' affiliations

Conrespondence...........

Correspondence to:
John S Lambert MD, PhD, Department of

Epidemiology and Public Health, Institute of Child Health, 30 Guilford Street, London WCIN 1EH, UK; lambert@umbi.umd.edu and jlambert@ich.ucl.ac. uk

Accepted for publication 21 May 2003

\begin{abstract}
Objectives: To evaluate the safety and feasibility of zidovudine and lamivudine (AZT/3TC) given to HIV infected pregnant women and their infants in Rio de Janeiro, Brazil.

Methods: This open label phase II study enrolled $40 \mathrm{HIV}$ infected antiretroviral naive women $\geqslant 20$ weeks gestation, CD4 $<500$ cells $\times 10^{6} / \mathrm{l}$, from two public hospitals. Treatment: fixed dose AZT $300 \mathrm{mg} / 3 T C$ $150 \mathrm{mg}$ by mouth every 12 hours until labour; AZT 300 mg by mouth every 3 hours until delivery; infants: AZT $4 \mathrm{mg} / \mathrm{kg}$ every 12 hours plus 3TC $2 \mathrm{mg} / \mathrm{kg}$ every 12 hours for 6 weeks. Blood haematology and chemistry were monitored; adherence evaluated by pills count; efficacy measured by changes in lymphocyte (CD4) and viral load, and by HIV RNA-PCR tests performed at birth, 6 and 12 weeks, to diagnose infant infection. No women breast fed.

Results: Patient characteristics: mean age 24.48 (SD 3.5) years; gestational age 24.5 (4.5) weeks; AZT/ 3TC duration 14.4 (4.4) weeks; vaginal delivery: 11/39; caesarean section: 28/39. Entry and pre-labour CD4: $310 / 486$ cells $\times 10^{6} / \mathrm{l}(\mathrm{p}<0.001)$; entry and pre-labour viral load: $53818 / 2616 \mathrm{copies} / \mathrm{ml}$ $(p<0.001)$. Thirty nine women tolerated treatment with $>80 \%$ adherence; one was lost to follow up. Five newborns were excluded from 3TC receipt. All 39 babies were uninfected. Haematological toxicity in newborns was common: anaemia in 27; neutropenia in five (two severe); platelets counts $<100000$ in two. All values recovered on study completion.

Conclusions: Fixed dose AZT/3TC is well accepted, gives improvements in CD4 and viral load; no infants were HIV infected. Haematological toxicity in infants needs careful monitoring.
\end{abstract}

S everal antiretroviral regimens have been shown to be effective in reducing mother to child transmission (MTCT) of HIV. ${ }^{1-3}$ Although there is increasing experience with the use of antiretroviral drugs in pregnancy, the safety data are not complete for many compounds. ${ }^{4-6}$ The first successful study for MTCT was reported in 1994, the PACTG 076 protocol, which demonstrated a $67 \%$ reduction of HIV transmission from mother to infant using zidovudine (AZT) monotherapy during gestation, intravenous during labour, and post partum for the newborn. ${ }^{1}$ The implementation of this prophylactic regimen administered to asymptomatic women, using different AZT regimens, showed consistent efficacy in many other studies. ${ }^{7}$ Later, the PACTG 185 showed extended benefit in reducing vertical transmission in more severely immunocompromised (CD4 cells $<200 \times 10^{6} / 1$ ) and symptomatic HIV infected pregnant women. ${ }^{8}$ Subsequently, new clinical trials were designed that demonstrated that the use of combined antiretroviral therapy was superior to AZT monotherapy for the treatment of adults and children infected by HIV; monotherapy, as a rule, is no longer recommended. 'Since 1997, the British HIV Association, the USPH in the United States, and the Brazilian Ministry of Health guidelines have recommended that, concerning antiretroviral treatment of HIV infected pregnant women, maternal health must be prioritised and if she requires treatment for her own health other drugs should be added to the 076 regimen. ${ }^{9-11}$

Information about the safety and tolerance of these drugs has been largely reported from animal studies, case reports, and a few clinical trials. There are few studies on the safety and pharmacokinetics of these agents in pregnant women. ${ }^{6}$ Of the five nucleoside reverse transcriptase inhibitors (NRTIs) only AZT and 3TC have been studied extensively in pregnant women, and new data are accumulating on nevirapine in ongoing clinical trials. ${ }^{12-14}$ Experience with these agents in international settings is limited.

The primary objectives of this study were to evaluate the maternal safety and tolerance of AZT/3TC in a fixed dose combination, administered twice a day during gestation, AZT every 3 hours orally during labour and post partum, and the safety and tolerance of AZT/3TC syrup given every 12 hours for 6 weeks to the newborn; in a population of Brazilian HIV infected pregnant women and exposed newborns. Secondary objectives were to evaluate the effect of AZT/3TC during gestation on the CD4 and viral load measurements in these mother-infant pairs.

\section{METHODS}

In an open label phase II safety and feasibility study, 40 HIV infected pregnant women were enrolled at two reference centres for the treatment of HIV infected pregnant women: at the Federal University of Rio de Janeiro (UFRJ) and at a federal public hospital, Raphael de Paula Souza (HRPS), both in the metropolitan area of Rio de Janeiro, Brazil, between May 1999 and June 2000. All women attending these two centres, who met eligibility criteria, were offered enrolment in the study. 


\section{Eligibility}

Inclusion criteria for pregnant women

HIV infection defined as two positive ELISA and one western blot; age $\geqslant 18$ years old; gestational age between 20 and 34 weeks of pregnancy (based on date of last menstrual period and/or ultrasound examination); CD4 count $<500$ cells $\times 10^{6} / \mathrm{l}$; haemoglobin $\geqslant 8.0 \mathrm{~g} / \mathrm{dl}$; haematocrit $>24 \%$; leucocytes $\geqslant 3000$ cells $\times 10^{6} / 1$ and neutrophil $\geqslant 1000$ cells $\times 10^{6} / \mathrm{l}$; platelets $\geqslant 100000$ cells $/ \mathrm{mm}^{3}$; transaminase (ALT) $<2.5 \times$ upper limit of normal (ULN); serum amylase $<2.5 \times$ SLN, creatinine $<1.5 \mathrm{mg} / \mathrm{dl}$; and receipt of a signed consent form by the patient.

\section{Exclusion criteria}

Previous or current use of other antiretroviral drug treatment; hypersensitivity to AZT or 3TC; chronic alcohol use; presence of intractable diarrhoea; presence of any opportunistic infection or severe bacterial infection within 2 weeks before enrolment; any cardiac, pulmonary, or obstetric complications; evidence of intrauterine fetal complications diagnosed by ultrasound.

\section{Exclusion criteria for the newborn}

Prematurity (age $\leqslant 36$ weeks of gestation); weight $<2500$ g; fetal abnormality incompatible with life; haemoglobin $<8.0 \mathrm{~g} / \mathrm{dl}$; leucocytes $<3000$ cells $\times 10^{6} / \mathrm{l}$ or neutrophil $<750$ cells $\times 10^{6} /$; platelets $<100000$ cells $\times 10^{6} / 1$; transaminases $>2.5 \times$ ULN; creatinine $>1.5 \mathrm{mg} / \mathrm{dl}$; and requirement for treatment for hyperbilirubinaemia (except phototherapy).

\section{Study design}

After 20 weeks of gestation, a fixed dose combination of AZT $300 \mathrm{mg} / 3 \mathrm{TC} 150 \mathrm{mg}$ (Biovir) administered every 12 hours was prescribed until labour; at which time $300 \mathrm{mg}$ of AZT (Retrovir) was given by mouth every 3 hours until delivery. Their infants received, within 12-24 hours following the last maternal dose of 3TC, AZT $4 \mathrm{mg} / \mathrm{kg}$ (Retrovir) syrup every 12 hours plus 3TC $2 \mathrm{mg} / \mathrm{kg}$ (Epivir) syrup every 12 hours for a period of 6 weeks. To measure adherence to treatment, study patients received a diary where any symptom was registered daily, and patients recorded if and when the drug was taken; the diary was checked and a pill count performed at each prenatal clinic visit. Safety was evaluated at each clinic visit (monthly until 28 weeks of pregnancy; biweekly from 28-36 weeks of pregnancy, and weekly beyond 36 weeks of gestation) by means of a standardised history and examination. Laboratory evaluation consisted of measurement of clinical haematology (haemogram and platelet count) and chemistry levels (ALT, AST, amylase, urea, creatinine) 2 weeks after starting therapy, monthly until 36 weeks of pregnancy, and then, following delivery, at 48 hours and at 2 and 6 weeks. Newborn safety and tolerance were monitored by clinical examination, haematological and biochemistry measurements at birth, and at 2 weeks and 6 weeks of age. Toxic effects were graded according to the USA criteria established by the adult and paediatric AIDS Clinical Trials Group organisation. Maternal efficacy of AZT/3TC fixed doses was measured by lymphocyte markers (CD4 count determined by flow cytometry) and viral load assays (RNA PCR-NASBA, Organon) performed at the UFRJ laboratory (the reference laboratory is certified by the Ministry of Health) at study entry, and after 36 weeks of pregnancy. HIV infection status of the infant was determined using RNA-PCR (viral load) assays performed within 48 hours of birth, at 6 weeks, and after 3 months. A child was considered infected if at least two RNA-PCR assays were positive. Women were strongly counselled not to breast feed and formula milk was provided free of charge for 1 year. This project was submitted and approved by the institutional review board of the two centres and also by the Brazilian national research ethics committee (CONEP).

\section{Statistical analysis}

The study questionnaire was entered into a PC computer using Epi-Info 6 (CDC) and analysed with SPSS for Windows (version 8.0). Discrete variables were analysed with $\chi^{2}$ statistics (Yates) and by Fisher's exact test (whenever expected values were $<5)$. Continuous variables were analysed by paired $t$ tests.

\section{RESULTS}

\section{Patient characteristics}

A total of 39 evaluable women are included in this analysis where there were data available through labour and delivery for full characterisation. They had a mean age of 24.4 years (median 24.0, SD 4.3), were mostly enrolled late in the second trimester (mean 25.4 weeks, median 23, SD 4.5), received a mean of 14.4 weeks of treatment during pregnancy (median 16, SD 4.4), and had a mean gestational age of 38.7 weeks at delivery (median 38.0, SD 1.2).

Mode of HIV transmission was heterosexual: 38/39; blood transfusion: 1/39. HIV infection status, as defined by the Centers for Disease Control: A2, 27/39 (69\%); A3, 8/39 (20.5\%); B2, 2/39 (5.1\%); B3, 2/39 (5.1\%); none was C category. Serological evidence of syphilis: $6 / 39$ (15.4\%). Thirty nine of 40 women completed the study, with no clinical or laboratory evidence of intolerance during gestation that required drug discontinuation or dose reduction. Mode of delivery: vaginal $11 / 39$ (28.2\%); caesarean section 28/39 (71.8\%) (emergency 17/39; elective 11/39). CD4 at entry: mean 310; median 304 cells $\times 10^{6} / \mathrm{l}$; range $76-495$ cells $\times 10^{6} / \mathrm{l}$. CD4 at $>36$ weeks: mean 468 ; median 457 cells $\times 10^{6} / 1$; range 82-999 ( $<<0.001)$. Entry VL: mean 53 818; median 18000 copies/ml (SD 84018 copies $/ \mathrm{ml}$ ); range 340 000-380 000 $(\mathrm{p}<0.001)$. Viral load prelabour: mean 2615; median 390 (SD 7201); range 0-44 $000(\mathrm{p}<0.001)$. Women represented a stratum of different immunological and virological values at entry (see table 1).

Thirty nine women completed the study with good tolerance of treatment during pregnancy; one patient was lost to follow up near labour. Rupture of membrane $<4$ hours was recorded in $91.9 \%$, mean 1.1 hour (SD 2.48). The major laboratory toxicity seen was anaemia during the prenatal period but no women required treatment interruption (see table 2). More than $80 \%$ of medications were taken by women as measured by pill count. No patient required interruption of therapy during gestation; AZT/3TC was well tolerated. Two women stopped therapy following birth because of low haemoglobin level $(\mathrm{Hg}:<8.00 \mathrm{~g} / \mathrm{dl})$ thought to be secondary to blood loss during delivery; one received a blood transfusion, and 10 days later AZT/3TC was restarted without any further problem

\section{Haematological parameters in mother and child}

As outlined in table 2, no statistically significant decreases in haematological parameters or increases in chemistries occurred in women, either in the prepartum or postpartum period. There was a drop in haemoglobin in the immediate postpartum period, thought to be a function of blood loss and haemodilution. In the newborn (table 3), there were statistically significant decreases in haemoglobin and haematocrit between week 2 and week 6 of age, but no significant changes in chemistry values in this time.

\section{Growth parameters of newborns}

All newborns were normal in weight, height, and head circumference when compared to standardised norms. These measurements included a mean birth weight of $3110 \mathrm{~g}$ 
Table 1 Immunological and virological parameters of study patients

\begin{tabular}{llll}
\hline & At entry & & $>36$ weeks \\
\cline { 2 - 2 } Variables & Mean, median, SD & & Mean, median, SD \\
\hline CD4 (cells $\times 10^{6} /$ I) & $310,304,124$ & $468,457,185.1$ \\
Viral load RNA - PCR copies/ml & $53818,18000,84018$ & & $2615,390,7201$ \\
CD4 (cells $\times 10^{6} /$ I) & At entry (No of patients) & $>36$ weeks (No of patients) \\
$<200$ & 10 & 3 \\
$200-350$ & 11 & 6 \\
$>350-500$ & 18 & 14 \\
$>500$ & 0 & 15 \\
Viral load (copies/ml) & 0 & 14 \\
Undetectable & 3 & 8 \\
$<1000$ & 5 & 12 \\
$1000<5000$ & 19 & 0 \\
$5000-50000$ & 11 & \\
$>50000$ & & \\
\hline
\end{tabular}

Table 2 Results of haematological and biochemistry examinations of pregnant women enrolled in Biovir study, Rio de Janeiro, Brazil

\begin{tabular}{|c|c|c|c|c|c|c|c|}
\hline Pregnant women & 1st visit (mean (SD)) & $\begin{array}{l}\text { Prepartum } \\
\text { (36 weeks) }\end{array}$ & p Value* & $\begin{array}{l}\text { Post partum 1st visit } \\
48 \text { hours post partum }\end{array}$ & $\begin{array}{l}\text { Last visit ( } 6 \text { weeks } \\
\text { post partum) }\end{array}$ & p Value ${ }^{* *}$ & p Value ${ }^{\star \star *}$ \\
\hline Haemoglobin & $11.20(1.15)$ & $11.50(1.03)$ & 0.21 & 10.01 (1.69) & 11.88 (1.30) & 0.001 & 0.002 \\
\hline Haematocrit & $33.20(2.46)$ & $34.03(4.08)$ & 0.21 & $29.83(5.32)$ & 35.37 (3.73) & 0.001 & 0.001 \\
\hline Neutrophils $\times 10^{3}$ & $4.86(1.64)$ & $4.77(1.08)$ & 0.66 & $6.62(2.15)$ & $3.08(1.27)$ & 0.001 & 0.000 \\
\hline AST & $18.40(6.90)$ & $20.40(6.90)$ & 0.15 & $22.76(12.85)$ & $24.83(13.30)$ & 0.58 & 0.03 \\
\hline ALT & $15.85(6.30)$ & $17.36(5.94)$ & 0.27 & $18.19(9.22)$ & $21.66(10.47)$ & 0.20 & 0.03 \\
\hline Amylase & $72.80(22.26)$ & $65.38(22.12)$ & 0.06 & 56.07 (23.3) & $56.48(24.00)$ & 0.93 & 0.009 \\
\hline Urea & $18.58(6.90)$ & $17.74(4.06)$ & 0.25 & $18.24(5.90)$ & 23.69 ( 9.74) & 0.02 & 0.04 \\
\hline Creatinine & $0.75(0.17)$ & $0.75(0.14)$ & 0.20 & $0.88(0.25)$ & $0.83(0.22)$ & 0.95 & 0.124 \\
\hline
\end{tabular}

Prenatal visits (40 women).

Values are mean (SD).

${ }^{*}$ Comparison between prepartum (36 weeks) and first visit. ${ }^{* *}$ Comparison between last visit ( 6 weeks post partum and first visit 48 hours post partum.

***Comparison between last visit (6 weeks post partum) and first visit.

Table 3 Results of haematological and biochemistry examinations of newborns enrolled in Biovir study, Rio de Janeiro, Brazil

\begin{tabular}{llll}
\hline Newborn & 2nd visit after birth (2 weeks) & 3rd visit after birth (6 weeks) & p Value \\
\hline Haemoglobin & $12.29(1.63)$ & $10.04(1.20)$ & $<0.001$ \\
Haematocrit & $36.58(4.94)$ & $29.44(3.99)$ & $<0.001$ \\
Neutrophils $\times 10^{3}$ & $2.91(1.38)$ & $2.72(1.54)$ & 0.68 \\
Platelets $\times 10^{3}$ & $457.0(123.9)$ & $423.8(123.6)$ & 0.22 \\
AST & $41.48(23.47)$ & $41.97(27.24)$ & 0.93 \\
ALT & $22.60(10.96)$ & $27.18(15.91)$ & 0.48 \\
Amylase & $18.63(15.68)$ & $30.75(25.90)$ & 0.07 \\
\hline Values are mean (SD). & &
\end{tabular}

(SD 450), mean head circumference of $33.7 \mathrm{~cm}$ (SD 1.43), and height of $47.9 \mathrm{~cm}$ (SD 2.57)

\section{Clinical course}

Five newborns did not receive 3TC because of study exclusion criteria: platelets $<100000$ (one); body weight $<2.500 \mathrm{~g}$ (two); neonatal icterus $>10$ bilirubin/ml (one); and one baby delivered in another hospital. ${ }^{1}$ All 39 babies are uninfected. Haematological toxicity in newborns was seen mostly following 4 weeks of therapy: anaemia, mild in 13 and moderate in 12; neutropenia, mild in two, moderate in one, and severe in two; platelets counts of $<100000$ were found in two children. All children had no symptoms related to these abnormalities and recovered from these findings without sequelae. There were two congenital abnormalities unrelated to the ARV drugs: (1) congenital megacolon where the mother began AZT/3TC at 22 weeks of pregnancy and the baby only received AZT because 3TC was excluded because of low birth weight - the diagnosis of megacolon was established 1 week after birth; (2) cardiac malformation (ventricular septal defect) where the mother began AZT/3TC at 33 weeks of pregnancy and the baby received AZT/3TC. All children have proved to be HIV uninfected with no positive PCR results.

\section{DISCUSSION}

The purpose of conducting the AZT/3TC fixed dose study in Rio de Janeiro was to assess the safety and tolerability, and to gain insight into the "efficacy" of this combination therapy when administered to HIV positive pregnant women. The study was designed at a time when pregnant women who were "sicker" than the population who had initially enrolled in the PACTG 076 study were presenting, and it was in a time when two drug therapy was considered a reasonable treatment option for patients infected with HIV. 
Of the original 40 women who enrolled in the study, 39 continued through the delivery and postpartum period, and adherence of the women to the compact regimen of one tablet twice daily was good; thus, this objective of the study was met. The five children who did not receive 3TC after delivery had criteria that excluded them, and a number of the children had abnormalities in white cell count (neutropenia, five) and in platelets (two). These abnormalities were a cause of concern to the clinicians, required more frequent follow up of the infant, and were an additional burden for the mother and the medical system. Although not a controlled study, these abnormalities are also seen in similar HIV exposed infants at the same clinic of the UFRJ who receive only ZDV.

In terms of response to therapy, as measured by surrogate markers, there were statistically significant increases in CD4 and drops in viral load in the women; because CD4 and viral load are predictors of MTCT of HIV, this probably explains why none of the children was infected. However, the sample size was small, the study was not controlled, and $79 \%$ of the mothers underwent a caesarean section, so it is difficult to comment on the efficacy of AZT/3TC. Although there were statistically significant decreases in viral load, only $36 \%$ of them became undetectable when measured close to delivery; ongoing viral replication can result in the development of viral resistance, and two drug therapy is no longer considered the standard of care for treatment. However, the drug combination was very well tolerated by the women in pregnancy and it can be argued that this combination may have a role in "short course" treatment in the last trimester of pregnancy, with discontinuation beyond this time. Such a strategy would minimise the possibilities of the development of viral resistance. Other studies have looked at viral resistance and it is clear that vertical transmission of HIV resistant virus to many classes of antiretrovirals can occur. ${ }^{15-18}$

A number of small phase 1 studies have been conducted with the AZT/3TC combination, revealing both initial safety and pharmacokinetic data on this combination. ${ }^{19-21}$ Of note, 3TC efficiently crosses the placenta, with similar levels in the umbilical cord as in the newborn circulation; median concentrations of 3TC in the amniotic fluid were up to five times higher than in the maternal plasma.

The French perinatal study, an observational cohort, which involves 85 centres throughout France, enrolled 445 women treated with standard ZDV as per the 076 protocol and then 3TC provided beyond 32 weeks and, subsequently, the combination administered to the child for 6 weeks. ${ }^{22}$ In total, 379 children received the full 6 weeks of AZT/3TC, while there were 40 children (9\%) with adverse effects most commonly haematological ( 30 cases) requiring discontinuation of one or more drugs. Common adverse events not requiring discontinuation included neutropenia and anaemia-similar to what has been found in our study. A recently published study from Thailand ${ }^{23}$ enrolled a total of 106 women, and demonstrated good safety in the mother, but some toxicities in the neonates including anaemia in six, elevated transaminases in one, and thrombocytopenia in three. As more women in the international arena are now being treated with combination therapy, there is a need to obtain safety information on the use of antiretrovirals in such diverse populations.

In summary, our study suggests that fixed dose of AZT/3TC is safe and efficacious when administered to the pregnant women infected with HIV; when this combination is given to the child, careful haematological monitoring is recommended. Additionally, while two drug combination therapy is no longer considered the "standard of care" and puts the mother at risk of developing viral resistance, short course treatment with this combination with discontinuation following delivery may be an important strategy in certain

\section{Key messages}

- The AZT/3TC combination is safe when administered to HIV infected pregnant women and their infants. In the postpartum period, we recommend careful monitoring for haematological toxicity for the infant.

- As more women in the international arena are receiving these drugs, alone or in combination, for the prevention of MTCT, there continues to be a need to obtain safety data in these women and their infants.

- Combivir (AZT/3TC combination) is capable of producing statistically significant improvements in CD4 count and viral load in HIV infected pregnant women.

settings. Such a strategy may minimise the risk of development of resistance and of safely treating the pregnant women late in pregnancy.

\section{ACKNOWLEDGEMENTS}

We are grateful to the participants in the study. We are grateful to UFRJ, IPPMG and the National Institutes of Health Fogarty International Programme of the University of Maryland, USA, for support, and to Glaxo Smith Kline, Rio de Janeiro, Brazil for financial support.

\section{CONTRIBUTORS}

Each of the authors who have been included in this manuscript were part of the "Biovir" team and were involved in its development, conduct, the summary and analysis of data, and review and critique of the manuscript: JL, development, conduct, summary/analysis, review, and critique; TA, development, conduct, summary; ESM, TPC, MB, MA, MH, and RB, development, conduct; MP, development, summary, statistical analysis; SAN, development, conduct, summary/analysis, review and critique.

\section{Authors' affiliations}

J S Lambert, University of Maryland Institute of Human Virology, Baltimore, Maryland, USA, and the Institute of Child Health, London, UK S A Nogueira, T Abreu, E S Machado, T P Costa, M Bondarovsky, M Andrade, M Perez, HUCFF/IPPMG/ME-Federal University of Rio de Janeiro, Brazil

M Halpern, R Barbosa, Hospital Raphael de Paula Souza (HRPS), Rio de Janeiro, Brazil

\section{REFERENCES}

1 Conner EM, Sperling R, Gelber R, et al. Reduction of maternal-infant transmission of HIV-1 with zidovudine treatment. N Engl J Med 1994:331:1173-80.

2 Grubert TA, Wintergeerst U, Lota-Friedreich R, et al. Long-term antiretroviral combination therapy including lamivudine in HIV-1 infected women during pregnancy. AIDS 1999;13:1430-1.

3 Saba J. The results of the PETRA intervention trial to prevent perinatal transmission in sub-Saharan Africa. From Sixth Conference on Retroviruse and Opportunistic Infections; 31 January-4 February 1999; Chicago, IL, Abstract S6.

4 Lorenzi P, Spicher VM, Laubereau B, et al. Antiretroviral therapies in pregnancy: maternal, fetal and neonatal effects. AIDS 1998;12:F241-7.

5 Koren G, Pastuszak A, Ito S. Drugs in pregnancy. N Engl J Med 1998:338:1128.

6 Taylor GP, Low-Beer N. Antiretroviral therapy in pregnancy: a focus on safety. Drug Saf $2001 ; 24: 683-702$

7 Mofenson LM. Perinatal exposure to zidovudine: benefits and risks N Engl J Med 2000;343:803-5.

8 Stiehm ER, Lambert JS, Mofenson LM, et al. Efficacy of zidovudine and human immunodeficiency virus (HIV) hyperimmune immunoglobulin for reducing perinatal HIV Transmission from HIV-infected women with advanced disease: results of Pediatric AIDS Clinical Trials Group Protocol 185. J Infect Dis 1999:179:567-75.

9 Perinatal HIV Guidelines Working Group. Public Health Service Task Force recommendations for the use of antiretroviral drugs in pregnant HIV-infected women for maternal health and interventions to reduce perinatal HIV-1 transmission in the United States, 5 December 2001. 
10 Dhalia C, Barreira D Castilho EA. A AIDS no Brasil: situacao atual e tendencias. Brasil: Ministerio de Saude, Boletim Epidemiologico-AIDS 2000;XIII:3-13.

11 Lyall EG, Blott M, de Ruiter A, et al. Guidelines for the management of HIV infection in pregnant women and the prevention of mother-to-child transmission. British HIV Association. HIV Med 2001;2:314-34.

12 Edwards SG, Larbalestier N, Hay P, et al. Experience of nevirapine use in a London cohort of HIV-infected pregnant women. HIV Med 2001:2:89-91.

13 Mirochnick M, Siminski S, Fenton T, et al. Nevirapine pharmacokinetics in pregnant women and in their infants after in utero exposure. Pediatr Infect Dis J $2001 ; 20: 803-5$

14 Guay A, Musoke P, Fleming T, et al. Intrapartum and neonatal single-dose nevirapine compared with zidovudine for prevention of mother-to-child transmission of HIV-1 in Kampala, Uganda: HIVNET 012 randomised trial. Lancet 1999;254:795-802.

15 Masquelier B, Chaix ML, Burgand M, et al. Zidovudine genotypic resistance in HIV-1-infected newborns in the French perinatal cohort. J Acquir Immune Defic Syndr 2001 ;27:99-104.

16 Johnson VA, Petropoulos CJ, Woods CR, et al. Vertical transmission of multidrug-resistant human immunodeficiency virus type 1 (HIV-1) and continued evolution of drug resistance in an HIV-1 infected infant. $J$ Infect Dis 2001; 183:1688-93
17 Kamkamidze G, Sullivan T, Charbonneau T. Occurrence of HIV-1 reverse transcriptase gene mutation at codon 215 in HIV-infected infants. J Clin Virol $2001 ; 22: 143-8$.

18 Clarke JR, Braganza R, Mirza A, et al. Rapid development of genotypic resistance to lamivudine when combined with zidovudine in pregnancy. $J$ Med Virol 1999:59:364-8.

19 Moodley J, Moodley K, Coovadia PH, et al. Pharmacokinetics and antiretroviral activity of lamivudine alone or when co-administered with zidovudine in HIV-1 infected pregnant women and their offspring. $J$ Infect Dis 1998:178:1327-33.

20 Mandelbrot L, Peytavin G, Firtion G, et al. Maternal-fetal transfer and amniotic fluid accumulation of lamivudine in human immunodeficiency virusinfected pregnant women. Am J Obstet Gynecol 2001;184:153-8.

21 Silverman NS, Watts DH, Hitti J, et al. Initial multicenter experience with double nucleoside therapy for human immunodeficiency virus infection during pregnancy. Infect Dis Obstet Gynecol 1998;6:237-43.

22 Mandelbrot L, Landreau-Mascaro A, Rekacewicz C, et al. Lamivudinezidovudine combination for prevention of maternal-infant transmission of HIV-1. JAMA 2001:285:2083-93.

23 Chaisilwattana $P$, Chokephaibulkit K, Chalermchockcharoenkit A, et al. Short course therapy with zidovudine plus lamivudine for prevention of mother to child transmission of human immunodeficiency virus type 1 in Thailand. Clin Infect Dis 2002;35:1405-13.

\section{GLOBAL VIEWS}

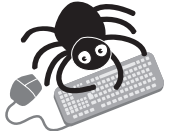

The full version of this report is on the STI website at wuw. stijournal.com
Cxually Transmitted Infections receives an increasing number of articles relating to prevalence of STIs or the performance of various syndromic management protocols in different populations. While these are very important for policymakers and clinicians locally, they tend to have limited applicability to other populations. For this reason we will publish these articles, after peer review, in full on eSTI. The paper edition of the journal will feature full abstracts in the "Global views" section.

\section{Prevalence of STDs among prostitutes in Czech border areas with Germany in 1997-2001 assessed in project "Jana"}

\section{Resl, M Kumpová, L Černá, M Novák, P Pazdiora}

Background: The STD problem emerged in the Czech Republic as a result of geopolitical and social and economic changes in the state. Prostitution is concentrated mainly around border areas with Austria and Germany, contributing to the increase in STDs. The CzechGerman project "Jana," based on a project umbrella network of the WHO, was organised. Objectives: To prevent STDs, including HIV/AIDS, and assessment of STD prevalence in the target group.

Methods: Prostitutes working in night clubs and in the streets and roads of three districts in the West Bohemian Region of the Czech Republic bordering on Germany were studied Interactions included street work, venereology check up, psychology and sociology counselling, psychological preparation on possible treatment, and continuous and regular contact.

Results: The number of "love clubs" involved in project "Jana" increased from 46 in 1997 to 72 in 2000. Of 561 street girls registered in the project during 1997-2001, there was one HIV positive, every 11 th prostitute had syphilis, and one in 93 women had gonorrhoea, whereas incidence of syphilis in the Czech Republic was 10.2/100 000 and that of gonorrhoea 9.5/100 000 inhabitants in 2001, 31 women had Chlamydia trachomatis urinary tract and genital infection, and 25 were HBsAg positives. STD frequency revealed in project participants significantly exceeds numbers of STDs in the other inhabitants of the Czech Republic. The majority of prostitutes were foreigners, mostly Ukrainians and Russians. Conclusion: The situation in the border areas is alarming. The priority must be to concentrate efforts on prevention of spread of venereal diseases in borders of economically disparate states.

A Sex Transm Infect 2003;79:e3 (http://www.stijournal.com/cgi/content/full/79/6/e3) 